\title{
Guérios, Paulo. 2016. Práticas do Filme Etnográfico. Curitiba: Editora UFPR, 168 pp.
}

\author{
NÁDIA PHILIPPSSEN FÜRBRINGER
}

Através de um caminhar minucioso pelas produções de pesquisadores, antropólogos ou não, que se dedicaram aos filmes etnográficos, Paulo Guérios apresenta ao leitor um livro baseado nas principais questões metodológicas que nortearam a produção desses filmes, seus processos de pesquisa e suas respostas estratégicas a tais questões. Destacando o caráter introdutório ao tema, o autor realiza um trabalho de fôlego ao construir a narrativa apresentando as diversas influências e suas polarizações, focando sempre na questão fílmica por meio de um texto didático ao leitor e apontando que todas as iniciativas são propostas e não definições finais e acabadas do campo em questão.

O livro inicia apresentando as produções pioneiras nas décadas de 1920 e 1930, que se tornariam clássicos na área exatamente por apresentarem os primeiros questionamentos metodológicos. Ainda que existam produções fílmicas com viés etnográfico antes de Nanook of the North, de 1920, produzido por Robert Flaherty, este foi o primeiro a deixar reflexões metodológicas que continuam inspirando debates no campo. Flaherty é figura fundadora dos filmes etnográficos e dos documentários em geral, mas não tinha uma formação na Antropologia, até mesmo porque o campo estava em construção. Seus filmes geralmente são criticados pela falta de cientificidade do seu propósito, questionando as encenações das práticas dos esquimós. Mas a reconstrução do modo de vida, proposto por Flaherty, tinha também uma função metodológica de engajar a plateia que assistia ao filme, por meio da construção conjunta, realizada com a participação dos sujeitos filmados. E essas duas práticas realizadas nesse filme etnográfico ecoam hoje por meio de reflexões sobre a objetividade das imagens, a participação dos sujeitos na produção dos registros fílmicos, dos limites entre realidade e como isso se coloca na reconstrução etnográfica.

De forma oposta, e complementar, às produções de Flaherty, estão as reflexões promovidas por Margaret Mead e Gregory Bateson em diversos livros, filmes e compilações fotográficas. Suas contribuições incidem não somente no campo da Antropologia Visual, mas nas teorias antropológicas como um todo. Inicialmente para cumprir um requisito de complemento visual ao trabalho que realizaram em Bali, com o passar dos anos centralizam o uso da imagem como um registro objetivo da pesquisa de campo, criando técnicas de registro dos dados imagéticos. As iniciativas desses pesquisadores geraram debates que são alimentados nos dias atuais, como por exemplo a relação entre o problema de pesquisa e o projeto fílmico, ou como orientar a captação das imagens a partir do problema de pesquisa, sem engessar a captação 
em registros. As críticas feitas aos trabalhos de Mead e Bateson foram de que essa falta de equilíbrio teria acarretado um uso meramente ilustrativo das imagens na pesquisa. Outro debate gerado pelas pesquisas deles diz respeito ao uso da linguagem verbal ou escrita junto à linguagem visual, como os diferentes regimes de relação podem ser estabelecidos entre o texto e a imagem. Nesse caso o texto prevalece ao uso das imagens, enquanto Flaherty usava pouco da linguagem textual para guiar seus filmes; são práticas opostas que têm influência em pesquisadores expoentes dos filmes etnográficos que são abordados no decorrer do livro. Por fim, outro debate importante que ecoa a partir das produções de Mead e Bateson refere-se à reflexão sobre a objetividade desses registros. Nesse ponto os dois pesquisadores mudaram suas posições acerca do tema, Mead sempre reivindicou o caráter objetivo da câmera no acontecimento ao qual registra e Bateson, a partir dos anos 1970, questiona tal objetividade. Em suma essa oposição entre "Bateson defendendo uma completa abertura ao caráter impreciso da linguagem visual, Mead argumentando pela domesticação de seu uso enquanto instrumento de ciência" (:43) reverbera e dinamiza o campo da Antropologia Visual até hoje.

São três estratégias de práticas do filme etnográfico que são identificados pelo autor e destrinchados nos capítulos que se seguem. Três posturas de pesquisa que se distinguem entre si, pela forma que se relacionam com aqueles que são filmados, na disposição do material técnico em campo e nas formas com as quais as edições na pós-produção do filme são realizadas. Essa forma de dividir os tipos de filmes etnográficos em três categorias tem um amplo debate dentro do campo da Antropologia Visual, o qual é detalhado por Guérios. A escolha por essa categorização indica mais uma vez o objetivo de construir um livro de caráter didático ao leitor, constantemente referenciando outros autores para aprofundar pontos caso seja do seu interesse, sobretudo enfocando filmes etnográficos de destaque.

Assim a primeira estratégia apresentada é denominada "filmes expositivos", que é discutida no segundo capítulo. As produções na década de 1970, do antropólogo Jerry Leach em parceria com o cineasta Gary Kildea, nas Ilhas Trobriand na Papua Nova Guiné, registraram a incorporação e ressignificação do jogo de críquete aos rituais tradicionais. Utilizando a reconstrução de situações para o registro fílmico, foi criticado por diversos expoentes da área, como Mead, além de usar excessivamente a linguagem verbal e textual em detrimento da imagem, o que carrega seus filmes com tantas informações que as imagens não são suficientemente responsivas. Porém outros filmes expositivos que produziram desdobramentos no campo do filme etnográfico foram os realizados por Robert Gardner. Ainda que tenha se aproximado do campo da Antropologia, seus filmes foram criticados por uma alta dose de autoridade etnográfica. Ao mesmo tempo Gardner sempre se mostrou consciente de todas essas escolhas em seus filmes, distanciando-se das monografias em Antropologia que guiavam os filmes da época, produzindo assim filmes mais alusivos e simbólicos. O processo criativo da criação do filme e suas escolhas nas edições, com e sem o apoio da linguagem textual, opõem-se às produções de Leach e Kildea, mas em ambos há a mesma intenção de resolver seus próprios problemas de pesquisa.

A segunda estratégia considerada por Guérios é a do "cinema observacional”, o qual é compreendido especialmente pela sua forma indutiva, na qual os acontecimentos guiam a sequência do roteiro e das filmagens; assim como o diretor se afasta do papel de narrador, tornando-se um mediador da audiência com as reflexões propostas pelo filme etnográfico. John Marshall é um expoente da área. Muito crítico, 
sempre apontou à audiência que para onde a câmera olha é um ponto de vista possível dentre outros, que são escolhas feitas constantemente que constroem o filme. Uma boa pesquisa feita previamente tornará aquele que filma mais preparado para os importantes eventos, podendo prever cenas reveladoras para filmar. Marshall também trabalhou com Timothy Asch, outro expoente da área do "cinema observacional". Ampliando uma técnica criada por Marshall, a "sequência de eventos", Asch organizava seus filmes a partir de uma unidade delimitada para análise. No momento da edição, Asch conseguia construir um argumento de caráter antropológico acerca da interação ocorrida em campo. O que se destaca nessa prática é que o problema de pesquisa é elaborado na edição, momento posterior à captação das imagens. Suas reflexões acerca da linguagem textual e do equilíbrio com o visual foram construídas nas suas diversas produções, da mesma forma que o debate sobre o uso ético das imagens produzidas também.

Um cineasta que segue repercutindo com suas reflexões sobre filmes etnográficos é David MacDougall. Seus filmes seguiam as características do cinema observacional, colocando o seu público sempre no papel de testemunha dos eventos. Para isso, certificava-se de realizar suas pesquisas com profundidade, garantindo imersão integral e atenção constante ao que se passa no campo enquanto filma. Seus filmes foram construídos ao mesmo tempo em que o registro era feito. Inicialmente, MacDougall, assim como outros expoentes do cinema observacional, acreditava que a câmera e o pesquisador/diretor deviam se esforçar ao máximo para atingir um nível de invisibilidade para aqueles que filmavam. Tratava-se de uma defesa da objetividade do registro fílmico. No entanto essa posição foi repensada por MacDougall, pois sabia que mantendo essa estratégia não retrataria o ponto de vista de quem é filmado. $\mathrm{O}$ cineasta tem efeito sobre aquilo que filma e a solução para esse dilema "seria a participação plena do pesquisador em cena e de seu interlocutor (o sujeito do cinema observacional) no processo de produção do filme." (: 107), um cinema participativo. MacDougall inspira-se nas produções anteriores feitas por Flaherty e Jean Rouch e começa a desenvolver outra estratégia para seus filmes.

O termo "participativo" considerava que câmera, diretor e interlocutor participavam na construção do filme. Essa ideia abre outra prática do filme etnográfico, destacada pelo autor como "filmes participativos". Jean Rouch é o maior destaque dessa estratégia. Seus filmes desde a década de 1950 eram calcados na imaginação e na exploração da experiência fílmica, para o pesquisador e também para seus espectadores.

A noção de participação foi radicalmente pensada por Rouch, já que se pretendia evidenciar a relação entre sujeitos, em que realidades etnográficas eram registradas no encontro dessas pessoas e por causa desse encontro, o que consequentemente teve desdobramentos diretos na teoria antropológica e, a partir dessas reflexões metodológicas acerca dos filmes de Rouch, a noção de Antropologia Compartilhada foi elaborada. Essa seria uma forma de fazer com que o conhecimento antropológico saísse dos espaços acadêmicos, pudesse ser compreendido, questionado e criticado fora dele; seus filmes eram um exemplo disso.

Outra noção elaborada por Rouch foi a exploração das possibilidades da imaginação na chamada “etnoficção". Foi o rompimento entre a fronteira da ficção e do documentário, nos quais os registros eram feitos sobre realidades imaginadas e representadas pelos interlocutores. Essa reflexão era feita tanto nas filmagens quanto nas edições após a produção, sendo que a montagem do filme era realizada por alguém que não o diretor, algo essencial para Rouch. Também a narração em seus filmes é muito destoante de outras estratégias; no caso, Rouch promove uma experiência de alteridade no público que assiste ao filme, 
estratégia consciente para alcançar a imaginação da plateia, construindo uma participação completa, desde os momentos iniciais da produção até a projeção.

Os filmes compartilhados de Jean Rouch tiveram forte influência na iniciativa brasileira do projeto "Vídeo nas Aldeias", no final da década de 1980. Compunham a equipe antropólogos e indigenistas que desenvolveram estratégias participativas de pesquisa e registro e acompanharam as apropriações das imagens feitas pelos indígenas, assim como a formação de jovens cineastas indígenas. Diversos povos indígenas fizeram filmes e o projeto, com mais de 20 anos de funcionamento, ressoou nas discussões dentro e fora da Antropologia acerca de teorias da representação, imagem etc., produzindo também, ao final, uma mudança na percepção da realidade ao redor desses povos indígenas, criando novas formas de articulação e de mediação de demandas dos grupos com a sociedade nacional.

Perspectivas do filme etnográfico, enquanto um campo de debate e pesquisa, são apresentadas para encerrar o livro. Recapitulando questões metodológicas abordadas no decorrer da obra, Paulo Guérios reforça sua cuidadosa investigação dos trabalhos que lhe pareceram interessantes e de destaque para a produção desse campo de conhecimento. Assim como as tendências dentro das universidades e das reflexões, demonstrando que nenhuma estratégia está engessada e elas podem, inclusive, serem usadas num mesmo filme. A questão é estar atento a esse pluralismo de abordagens para um desenvolvimento da consciência metodológica, essencial na prática do filme etnográfico.

Nádia Philippssen Fürbringer é graduada em Ciências Sociais pela Universidade Federal do Paraná (UFPR), mestre e doutoranda em Antropologia Social pela Universidade Federal de Santa Catarina (Ufsc).

RECEBIDO: $27 / 07 / 2018$

APROVADO: 18/12/2018 